\title{
The Examination of Air Blowing Method and Thermal Comfort of Variable Air Conditioning System using Coanda Effect
}

\author{
Hikari Sakakibara ${ }^{1, *}$, Takashi Akimoto ${ }^{1}$, Hitomi Igarashi $^{2}$, Shunsuke Nakamura ${ }^{3}$, and Madoka Kimura ${ }^{1}$ \\ ${ }^{1}$ Shibaura Institute of Technology, 3-7-5, Toyosu, Koto, Tokyo 135-8548, Japan \\ ${ }^{2}$ Shinryo Corporation, 41, Wadai, Tsukuba, Ibaraki 300-4247, Japan \\ ${ }^{3}$ Mitsubishi Jisho Sekkei Inc., Marunouti 2-chome Building, 2-5-1, Marunouchi, Chiyoda, Tokyo 100-0005, Japan
}

\begin{abstract}
The "Strategic Energy Plan" implemented by the Cabinet of Japan in 2014 strives for zero energy building design for typical new construction by 2030 . The present study focuses on a ductless and variable air conditioning system, using the Coanda effect, with the aim of reducing fan power, and saving of resources by reducing the space between the ceiling. In this study, we examined the air blowing method and evaluated thermal comfort using computational fluid dynamics as well as subjective perception of coolness in a midsize office. A draft zone was reduced by extending the interval between conditioned air outlets. However, if the extension of throw length was excessive, hot space would be formed near the air outlets, and there would be a risk of impacting thermal comfort. Moreover, we confirmed that the thermal comfort was generally favourable. In particular, perceived thermal comfort was better at the position in the office where the air flow landed on the upper body of the subjects. On the other hand, it decreased when the influence of the air flow was small, and at the point where air flow landed on the lower body of the subjects.
\end{abstract}

\section{Introduction}

In Japan, the "Strategic Energy Plan" implemented by the Cabinet in 2014 sets the goal of realizing a net zero energy building (ZEB) for the typical new construction by 2030 [1]. As part of this effort, in this study, we focus on the variable-air-conditioning-system using the Coanda effect, which is a ductless-air-conditioningsystem [2]. The variable-air-conditioning-system is shown in Fig. 1. The Coanda effect describes the characteristic of air flow along the ceiling surface. The ceiling duct is located to blow conditioned air from the wall position near the ceiling, and the floor height is reduced while securing the ceiling height to minimize the structure load. This air conditioning system has attracted attention as one of the popularized approaches of ZEB.

In this study, we examined the blowing method of the variable-air-conditioning-system using the Coanda effect with computational fluid dynamics (CFD) analysis for an environmentally-friendly office building (Table 1) scheduled to be completed in 2020. Moreover, we conducted subjective perception experiments and thermal comfort evaluation.

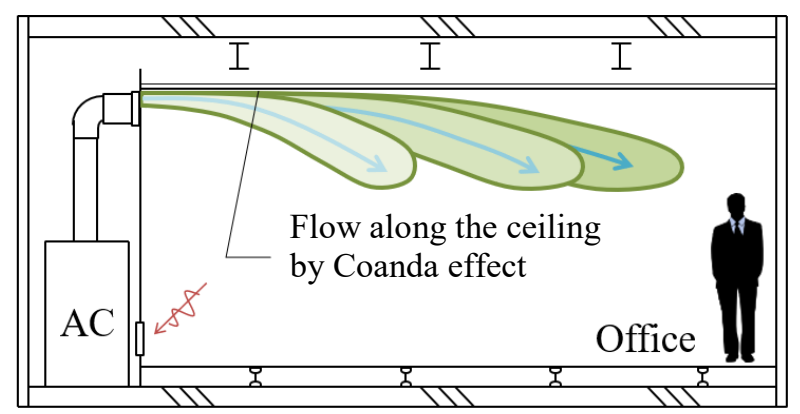

(a) System Overview

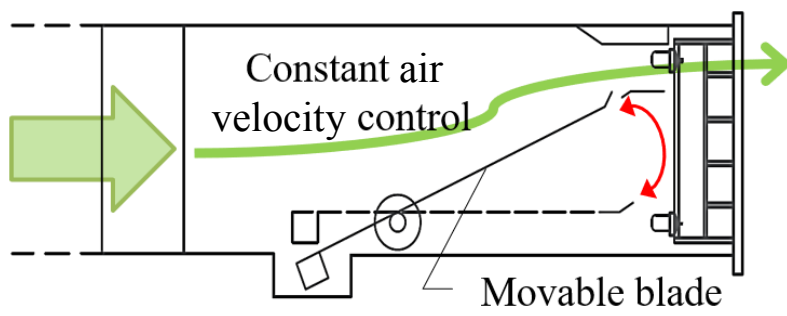

(b) Cross-section view of an air outlet

Fig. 1. Overview of a variable-air-conditioning system using the Coanda effect

\footnotetext{
*Corresponding author: me18047@shibaura-it.ac.jp
} 
Table 1. Architectural overview

\begin{tabular}{|c|c|c|c|}
\hline Location & \multicolumn{3}{|c|}{ Chiyoda, Tokyo, Japan } \\
\hline Principal Use & \multicolumn{3}{|c|}{ Office } \\
\hline Site Area & \multicolumn{3}{|c|}{$595 \mathrm{~m}^{2}$} \\
\hline Construction Area & \multicolumn{3}{|c|}{$506 \mathrm{~m}^{2}$} \\
\hline Total Floor Area & \multicolumn{3}{|c|}{$4,656 \mathrm{~m}^{2}$} \\
\hline Construction & \multicolumn{3}{|c|}{$\begin{array}{l}\text { Steel Construction, Steel-Reinforced } \\
\text { Concrete }\end{array}$} \\
\hline Story & \multicolumn{3}{|c|}{$10(\mathrm{~B} 1 \mathrm{~F} \sim 8 \mathrm{~F})$} \\
\hline Floor Height & $3.45 \mathrm{~m}$ & Ceiling Height & $2.8 \mathrm{~m}$ \\
\hline Commencement & 2018 & Completion & 2020 \\
\hline
\end{tabular}

\section{Examination of blowing method by CFD analysis}

\subsection{Purpose of analysis}

The variable-air-conditioning-system using the Coanda effect may cause a draft, which is a local, often unpleasant airflow in the residential area (floor $(\mathrm{FL})+0$ to $1.7 \mathrm{~m}$ ) [3]. Therefore, to reduce this uncomfortable draft, we examined the air flow method using CFD analysis for one floor in the target office building.

\subsection{Analysis summary}

Figure 2 illustrates the analysis model, and Table 2 presents the analysis parameters. We created a model with the thermal fluid analysis tool STREAM V12, and reproduced a floor of the office building at 12 o'clock in Tokyo during summer. The target floor has two air outlets on the upper part of one side of the wall with a large aspect ratio per span, and air inlets at the upper (1) and lower parts (2) of the opposing wall facing the air outlets, as well as on the lower part of the wall (3) on the same side as the air outlets.

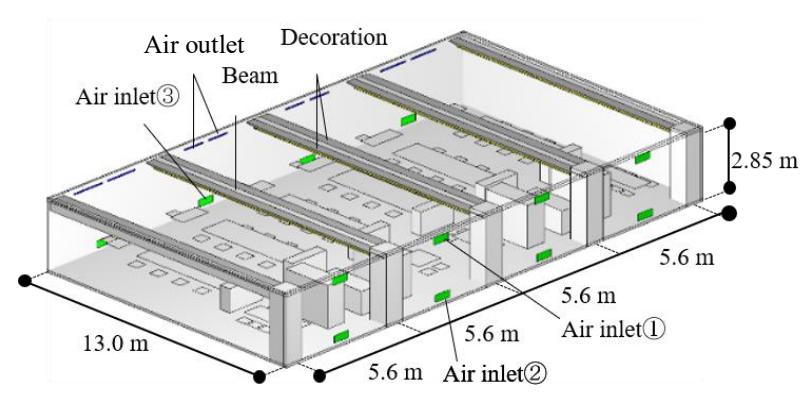

Fig. 2. Analysis model
Table 2. Analysis overview

\begin{tabular}{|c|c|}
\hline Location & Tokyo, Japan \\
\hline Season & 12 O'clock in Summer $^{\prime}$ \\
\hline Room Temperature & $26^{\circ} \mathrm{C}$ \\
\hline Air Outlet Width & $1,500 \mathrm{~mm}$ \\
\hline Air Outlet Height & $14 \sim 79 \mathrm{~mm}$ \\
\hline Structure Load & $2,927 \mathrm{~W}$ \\
\hline Lightning Load & $2,536 \mathrm{~W}$ \\
\hline Human Load & $4,247 \mathrm{~W}$ \\
\hline Equipment Load & $7,925 \mathrm{~W}$ \\
\hline
\end{tabular}

In the mesh division, the first cell width from the wall surface was constructed to be of 10 to $20 \mathrm{~mm}$. The aspect ratio was set to 10 at the maximum. The cell width was about $100 \mathrm{~mm}$. The mesh division was done in detail, particularly around the air outlets and the wall. The standard $\mathrm{k}-\varepsilon$ turbulence model was used to calculate conditions, and the SIMPLEC method was adopted for the analysis. We used the QUICK scheme as the difference scheme in the advection term of the equation of motion.

Table 3 shows the analysed cases. Fifteen cases were analysed at thermal load ratios of $30 \%, 50 \%$ and $100 \%$. The default case (Case 1 ) was set to $3 \mathrm{~m} / \mathrm{s}$ for the air velocity, $8{ }^{\circ} \mathrm{C}$ for the outlet temperature difference, $100 \mathrm{~mm}$ for the blowout port height, and $\mathrm{CH}-100 \mathrm{~mm}$ for the outlet height. The suction rates was $50 \%$ for each air inlets (3) and (1) on the opposing walls.

\subsection{Analysis results}

The air diffusion performance index (ADPI) is the volume ratio of the comfort zone in the residential area (floor +0 to $1.7 \mathrm{~m}$ ) to the entire zone of measurement, in the range around the effective draft temperature (EDT). EDT is an index of the draft obtained from different temperatures and air velocity. We defined the throw length as the average distance from each air outlets to the position where the air velocity near the ceiling is equal to or less than $0.25 \mathrm{~m} / \mathrm{s}$. Table 4 shows the throw lengths and the calculated ADPI of all analysed cases. Table 5 shows the analysis results for Cases 1, 6, and 14, when the thermal load rate was $100 \%$.

In Case 2, the throw length exceeded Case 1 at all thermal load rates. Thus, we consider that the throw length tends to extend as air velocity increases. 
Table 3. Parameters of the analysed cases

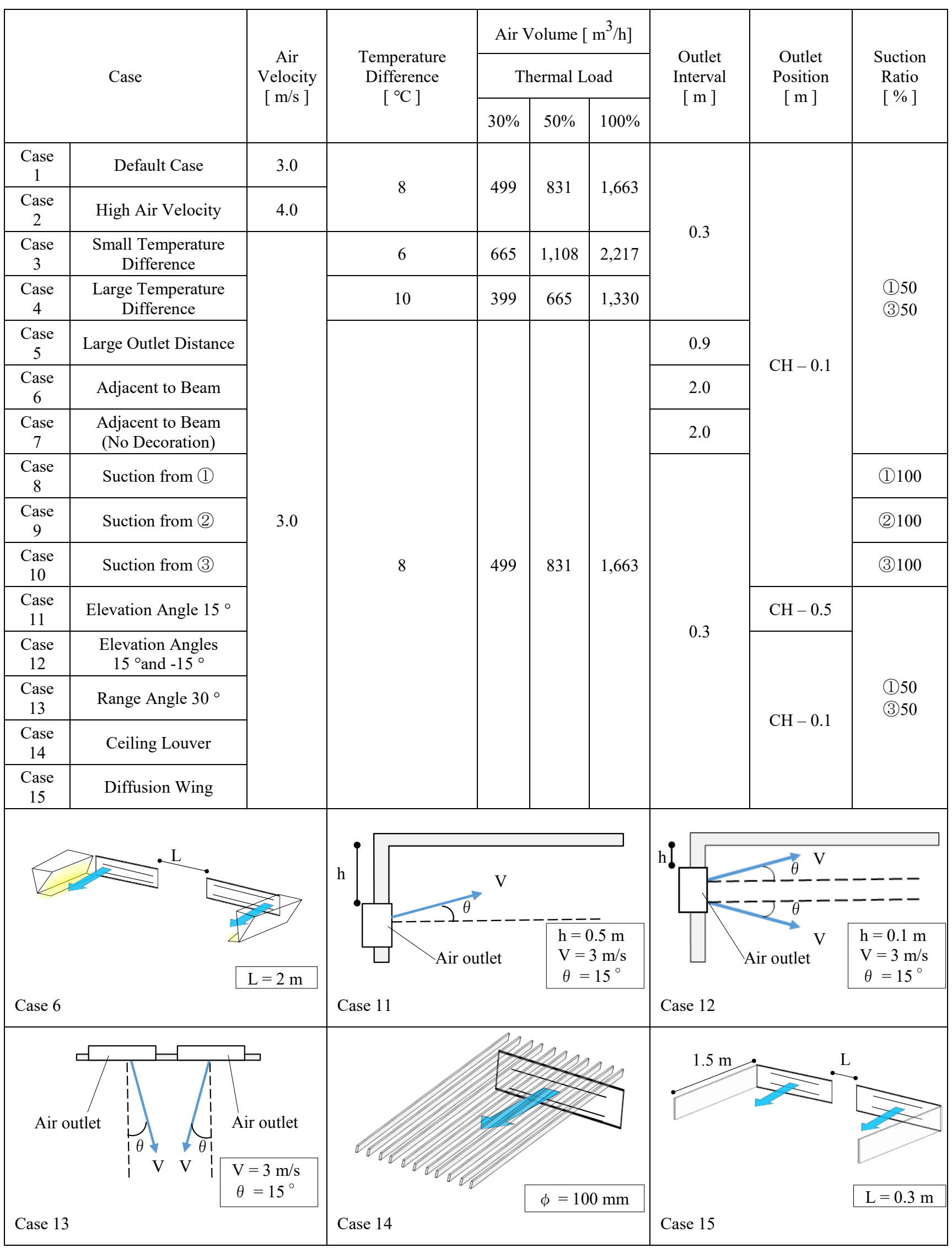


Table 4. Throw lengths and ADPI. Relative values compared to the default case are color-coded.

\begin{tabular}{|c|c|c|c|c|c|c|}
\hline \multirow{2}{*}{ Case } & \multicolumn{2}{|c|}{ Throw length [ $\mathrm{m}$ ] } & \multicolumn{3}{c|}{ ADPI [\%] } \\
\cline { 2 - 7 } & \multicolumn{2}{|c|}{ Thermal Load } & \multicolumn{3}{c|}{ Thermal Load } \\
\cline { 2 - 7 } & $30 \%$ & $50 \%$ & $100 \%$ & $30 \%$ & $50 \%$ & $100 \%$ \\
\hline Case 1 & 4.8 & 7.4 & 9.2 & 97 & 93 & 85 \\
\hline Case 2 & 6.5 & 8.9 & 12.0 & 97 & 95 & 84 \\
\hline Case 3 & 7.4 & 9.2 & 12.5 & 96 & 93 & 84 \\
\hline Case 4 & 4.0 & 5.7 & 7.8 & 96 & 92 & 83 \\
\hline Case 5 & 4.4 & 6.5 & 7.5 & 97 & 95 & 86 \\
\hline Case 6 & 5.4 & 6.3 & 9.5 & 99 & 97 & 87 \\
\hline Case 7 & 5.1 & 8.1 & 10.5 & 98 & 95 & 84 \\
\hline Case 8 & 5.1 & 7.0 & 8.7 & 96 & 93 & 86 \\
\hline Case 9 & 5.2 & 7.1 & 9.3 & 97 & 93 & 81 \\
\hline Case 10 & 5.2 & 7.3 & 8.7 & 97 & 94 & 83 \\
\hline Case 11 & 5.0 & 7.3 & 8.4 & 98 & 94 & 79 \\
\hline Case 12 & 4.5 & 5.8 & 8.9 & 95 & 90 & 72 \\
\hline Case 13 & 3.9 & 4.9 & 5.8 & 94 & 90 & 77 \\
\hline Case 14 & 8.1 & 12.0 & 12.9 & 95 & 80 & 74 \\
\hline Case 15 & 4.6 & 7.3 & 9.5 & 97 & 94 & 87 \\
\hline \multirow{2}{*yyyyyy}{} & & & Case 1 & & & Max. \\
\hline
\end{tabular}

Cases 1, 3, and 4 exhibit the tendency for the peel distance to extend with decreasing temperature difference in blowing air.

For Cases 5, 6, and 7, ADPI exceeds Case 1 at all loading rates. This observation indicates that expansion of the interval between adjacent outlets reduces the heat pool and the draft, improving the perceived comfort. Moreover, by blowing out adjacent to the beam, the throw length is prolonged as air flow is stabilized, because the beam prevents air from being drawn to one side of the neighbouring surfaces.

Cases 8,9 and 10 indicate that the influence of the suction positions on the throw length is not significant. In Cases 11, 12, and 13, the throw lengths and ADPI at the thermal load rate of $100 \%$ were both lower than in Case 1. We assume that this is due to the influence of the imposed angles on the air current.
Table 5. Isosurface of air velocity and discomfort space

\begin{tabular}{|c|c|}
\hline $\begin{array}{c}\text { Isosurface of Air Velocity } \\
\text { Dark: Attached Air Flow } \\
\text { Pale: Reached Air Flow } \\
(0.25 \mathrm{~m} / \mathrm{s})\end{array}$ & $\begin{array}{c}\text { Discomfort Zone in terms of } \\
\text { EDT } \\
\text { (EDT }<-1.7) \\
\text { Red: Hot Space } \\
\text { (EDT }>1.1)\end{array}$ \\
\hline & \\
\hline
\end{tabular}

In Case 14, the throw length exceeded Case 1 at all thermal load rates. However, heat accumulation occurred in the space to the side of the air conditioner, and ADPI values fell below $80 \%$ at $100 \%$ thermal load.

In Case 15, the throw length decreased when the thermal load rate was $50 \%$ or less. On the other hand, ADPI was improved at all thermal load rates. This is understood to be a result of reduced interference of adjacent blown air currents and improved diffusibility.

Consequently, excessive elongation of the throw length shows a reduction in draft. Nevertheless, overall perceived comfort may be simultaneously decreased due to generation of hot space. Furthermore, increase in the air outlet interval and velocity of the blown air current in the horizontal direction reduces the draft, which is considered to improve comfort.

\footnotetext{
* Corresponding author: me18047@shibaura-it.ac.jp
} 


\section{Experimental evaluation using subjects}

\subsection{Purpose of experiments}

The variable-air-conditioning-system using the Coanda effect may bring discomfort to occupants due to draft and heat accumulation. Therefore, the subjects' perception of thermal comfort was evaluated in experiments conducted along the room span of the office building.

\subsection{Outline of experiments}

Figure 3 outlines the full-scale chamber and environmental measurement conditions. Table 6 presents the experimental parameters. Experiments were conducted from 10:30 to 17:00 on September $21^{\text {st }}$ to $25^{\text {th }}, 2017$. We built a full-scale chamber that replicated one span of the target office building, mimicking summer heat at 12 o'clock in Tokyo. Based on the results of the previous section, the blowing temperature difference was set to $10{ }^{\circ} \mathrm{C}$ in an effort to improve energy savings. Furthermore, the distance between the outlets was set at $1.8 \mathrm{~m}$ to improve comfort.

Room temperature was the average air temperature measured from two air inlets. The structure load was reproduced with 12 radiation panels, the lighting load was reproduced by a LED light guide plate, and the equipment load was reproduced with nine simulated loads (ribbon heaters). Assuming an occupancy of 14 people, the human load was reproduced with 10 simulated loads, 3 subjects and 1 experimenter at a time.

The subjects were 5 men and 4 women in their 20 s to 50s. Subjects were placed at three positions from Point $A$ to Point $C$ in the chamber. The subjects wore the same clothes, following the Cool Biz campaign guideline (0.5 clo) [4].
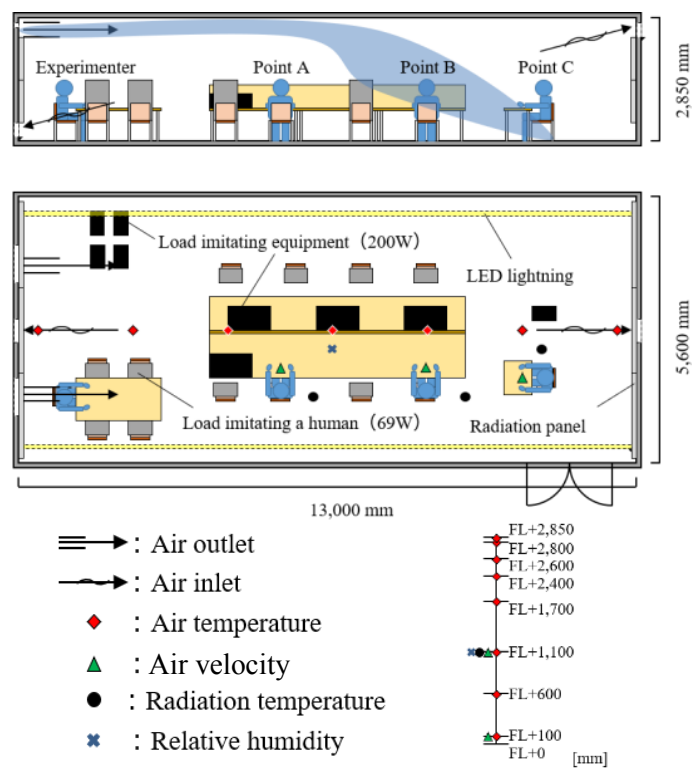

Fig. 3. Overview of full-scale environmental chamber
Table 6. Experimental parameters for subjects' perception experiments

\begin{tabular}{|c|c|}
\hline Assumed Location & Tokyo, Japan \\
\hline Assumed Season & 12 O'clock in Summer $^{\prime}$ \\
\hline Blowing Air Velocity & $3.0 \mathrm{~m} / \mathrm{s}$ \\
\hline Blowing Air Volume & $1114 \mathrm{~m}^{3} / \mathrm{span}$ \\
\hline Room Temperature & $26^{\circ} \mathrm{C}$ \\
\hline Temperature Difference & $10^{\circ} \mathrm{C}$ \\
\hline Air Outlet Width & $750 \mathrm{~mm}$ \\
\hline Air Outlet Height & $69 \mathrm{~mm}$ \\
\hline Outlet Interval & $1.8 \mathrm{~m}$ \\
\hline Outlet Position & $\mathrm{CH}-0.1 \mathrm{~m}$ \\
\hline Structure Load & $374 \mathrm{~W}$ \\
\hline Lightning Load & $576 \mathrm{~W}$ \\
\hline Human Load & $966 \mathrm{~W}$ \\
\hline Equipment Load & $1,800 \mathrm{~W}$ \\
\hline
\end{tabular}

Figure 4 illustrates the experimental procedure. Subjects are seated at Point A where the blowing air current does not strike the body, at Point B where the blowing air current mainly lands on the upper body, and at Point $\mathrm{C}$ where the blowing air current mainly lands on the lower body. Subjects stayed in the environment, resting in a chair for 50 minutes. Afterwards, each of the subjects was instructed to type on a keyboard for 10 minutes. Subsequently, we administered a questionnaire to quantify a psychologically perceived response from the subjects [5].

$\left.\begin{array}{|l}\text { Entering } \\ \text { the room }\end{array}\right\rangle \quad \begin{gathered}\text { Rest in the chair } \\ (50 \mathrm{~min})\end{gathered} \quad \sum \begin{gathered}\text { Typing } \\ (10 \mathrm{~min})\end{gathered} \quad \sum_{\text {sponse }}^{\text {Re- }}$

Fig. 4. Experimental procedure

\subsection{Experimental results}

\subsubsection{Environment measurement results}

Table 7 shows the environmental measurement results. The thermal comfort index is defined as SET*, and the draft index EDT is obtained from the measured values.

At Point A where the blown air current did not hit the body, SET* exceeded the air temperature at FL + $1,100 \mathrm{~mm}$, with a sensation of "slightly warmer, somewhat uncomfortable," deviating from the comfortable range. A draft was not observed based on the EDT. 
Table 7. Experimental conditions

\begin{tabular}{|c|c|c|c|c|c|c|c|}
\hline Point & $\begin{array}{l}\text { Measurement } \\
\text { Position } \\
{[\mathrm{mm}]}\end{array}$ & $\begin{array}{l}\text { Air } \\
\text { Temperature } \\
{\left[{ }^{\circ} \mathrm{C}\right]}\end{array}$ & $\begin{array}{l}\text { Radiation } \\
\text { Temperature } \\
\quad\left[{ }^{\circ} \mathrm{C}\right]\end{array}$ & $\begin{array}{l}\text { Air } \\
\text { Velocity } \\
{[\mathrm{m} / \mathrm{s}]}\end{array}$ & $\begin{array}{l}\text { Relative } \\
\text { Humidity } \\
\quad[\%]\end{array}$ & $\begin{array}{l}\mathrm{SET}^{*} \\
{\left[{ }^{\circ} \mathrm{C}\right]}\end{array}$ & $\begin{array}{l}\mathrm{EDT} \\
{\left[{ }^{\circ} \mathrm{C}\right]}\end{array}$ \\
\hline \multirow{2}{*}{ Point A } & $\begin{aligned} & \text { FL } \\
&+1,100\end{aligned}$ & 25.9 & \multirow{2}{*}{27.0} & 0.12 & \multirow{6}{*}{46.1} & 26.0 & 0.1 \\
\hline & $\begin{array}{c}\text { FL } \\
+100\end{array}$ & 25.6 & & 0.20 & & 25.4 & -0.7 \\
\hline \multirow{2}{*}{ Point B } & $\begin{array}{c}\text { FL } \\
+1,100\end{array}$ & 25.1 & \multirow{2}{*}{26.2} & 0.31 & & 23.9 & -2.2 \\
\hline & $\begin{array}{c}\text { FL } \\
+100\end{array}$ & 25.3 & & 0.20 & & 24.8 & -1.1 \\
\hline \multirow{2}{*}{ Point $\mathrm{C}$} & $\begin{array}{c}\text { FL } \\
+1,100 \\
\end{array}$ & 25.6 & \multirow{2}{*}{26.8} & 0.26 & & 24.7 & -1.3 \\
\hline & $\begin{array}{c}\text { FL } \\
+100 \\
\end{array}$ & 25.6 & & 0.34 & & 24.2 & -2.0 \\
\hline \multicolumn{8}{|c|}{$\begin{array}{l}\text { SET*: Standard New Effective Temperature }\left[{ }^{\circ} \mathrm{C}\right] \\
\text { Sensed temperature while resting in a seat, clothing } 0.6 \text { clo, } \\
\text { ture = radiation temperature, air velocity } 0.1 \mathrm{~m} / \mathrm{s}, 50 \% \text { relative humidity. } \\
\text { Comfortable sensation is defined as } 22.2 \leq \mathrm{SET}^{*} \leq 25.6\left[{ }^{\circ} \mathrm{C}\right] \text {. }\end{array}$} \\
\hline
\end{tabular}

At Point B where the blowing air current lands on the upper body, SET* is in the comfortable range, i.e. bringing a "comfortable, acceptable" sensation, but the EDT was confirmed to be off the comfortable range at $\mathrm{FL}+1,100 \mathrm{~mm}$. At the air temperature, SET* and EDT respectively, the value of $\mathrm{FL}+1100 \mathrm{~mm}$ is lower than the value of $\mathrm{FL}+100 \mathrm{~mm}$, and the temperature was reversed above and below.

At Point $\mathrm{C}$ where the blowing air current lands on the lower body, SET* is within the comfortable range, providing a "comfortable, acceptable" sensation. However, at the height of FL $+100 \mathrm{~mm}$, EDT values were outside of the comfortable range and a draft was observed. In addition, the air temperature is equal for FL $+100 \mathrm{~mm}$ and FL $+1,100 \mathrm{~mm}$, however the values of SET $^{*}$ and EDT at FL $+100 \mathrm{~mm}$ are lower than those at $\mathrm{FL}+1,100 \mathrm{~mm}$.

\subsubsection{Psychological measurement results}

Figure 5 shows the percentage of thermal sensation among seven defined classes ranging from cold to hot. At Point A, "slightly warm" was the most common response, while at Points $\mathrm{B}$ and $\mathrm{C}$, "slightly cool" was the most frequent one.

Figure 6 shows the distribution of thermal sensation and comfort. At Point A, responses of "slightly uncomfortable" were obtained, but generally, "comfort" prevailed. At Point $\mathrm{B}$, all responses were within the "comfortable" zone. At Point C, "slightly uncomfortable" was observed, but generally "comfort" prevailed.

Figure 7 shows the distribution of thermal sensation and acceptance. Responses of "acceptable" were obtained at all points.

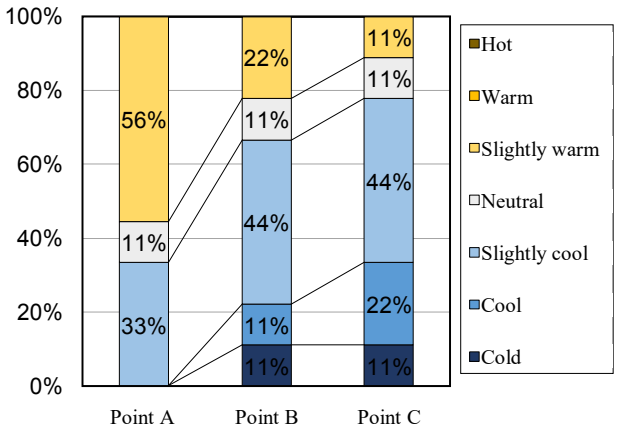

Fig. 5. Percentage of thermal sensation by class

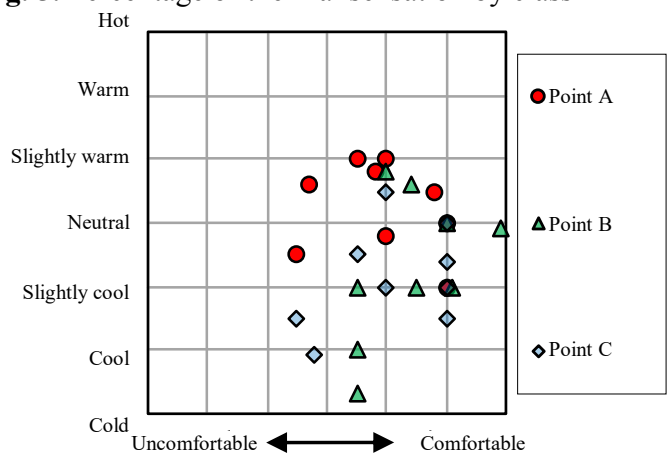

Fig. 6. Distribution of thermal sensation and comfort

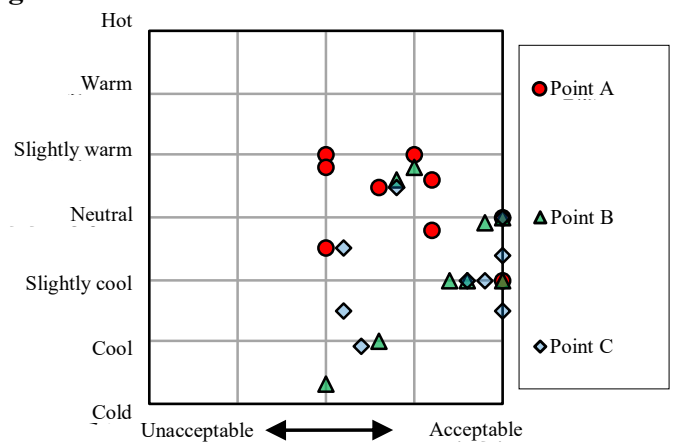

Fig. 7. Distribution of thermal sensation and acceptance

\footnotetext{
* Corresponding author: me18047@shibaura-it.ac.jp
} 
Figure 8 shows the distribution of air flow sensation. At Point A, response of "slightly felt" was the most frequent. At Points B and C, response of "felt" was the most frequent.

Figure 9 shows the distribution of air flow sensation and comfort. At Point A, all responses were in the "comfortable" range, except for one "very felt, slightly uncomfortable". At Point B, all responses were in the "comfortable" range, except for one "felt, uncomfortable". At Point C, responses were mixed among "slightly felt, slightly uncomfortable", "felt, uncomfortable", and "very felt, slightly uncomfortable", but they were all generally comfortable responses.

Figure 10 shows the distribution of air flow sensation and acceptance. At Points A and B, all responses were in the "acceptable" range. At Point $C$, one "felt and unacceptable" was observed, while the rest were within the "acceptable" range.

\subsection{Consideration of experiments}

We examined the results of environmental measurements of subjects' perception in the experiment.

At Point $\mathrm{A}$ where the blowing air current does not hit the body, the response of "slightly uncomfortable" in thermal sensation comfort corresponded to SET* at FL + $1,100 \mathrm{~mm}$. We presume that this was strongly influenced by radiant heat due to the absence of air flow. Additionally, although not confirmed by EDT, the low air current flowing along the floor could be the reason behind the responses of "slightly uncomfortable" in thermal sensation comfort and "uncomfortable" in airflow comfort.

At Point B where blowing air current lands on the upper body, the response of "discomfort" in the air flow comfort corresponded to EDT at FL $+1,100 \mathrm{~mm}$. Otherwise, all responses were in the "comfortable" range for thermal sensation comfort. This is considered to be the result of upper and lower temperatures being reversed by the air current separated from the ceiling surface and the subject's head was cool [6].

At Point $\mathrm{C}$ where the blowing air current lands on the lower body, the response of "unacceptable" in the air flow sensation corresponded to the EDT value at FL + $1,100 \mathrm{~mm}$. The response of "slightly uncomfortable" in the thermal sensation comfort is again considered to be due to the draft.

\section{Conclusion}

In this study, we examined the air flow of the variable-airconditioning-system using the Coanda effect and evaluated thermal comfort calculations as well as subjective perception.

Consequently, we conclude that increase in the air outlet interval and diffusion of the air current in the horizontal direction improve comfort level.

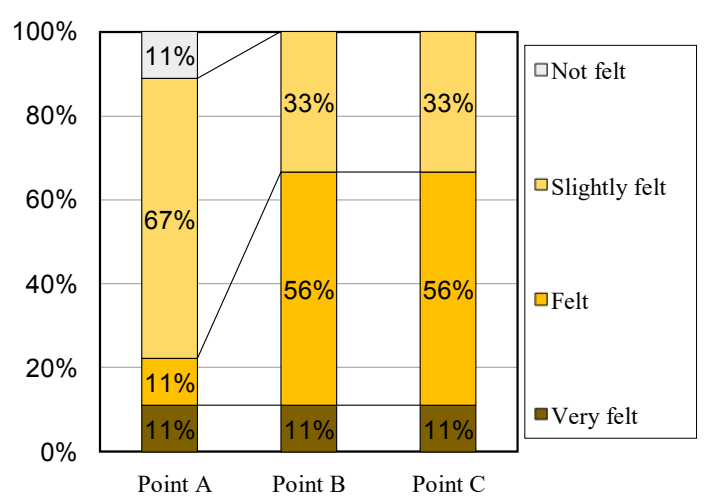

Fig. 8. Percentage of air flow sensation by class

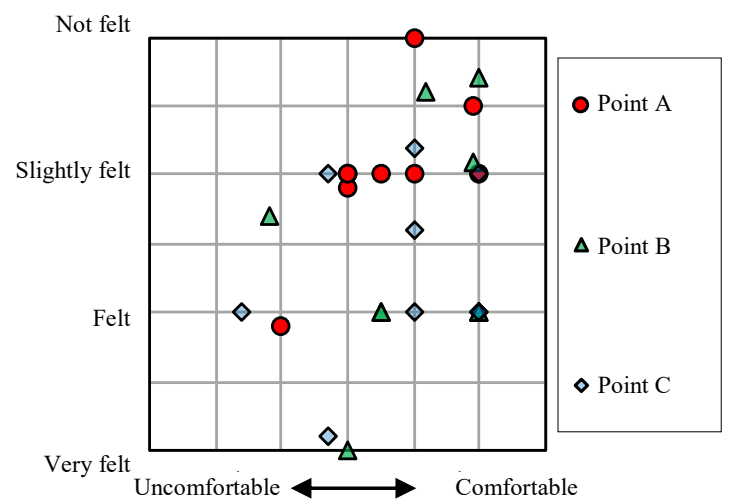

Fig. 9. Distribution of air flow sensation and comfort

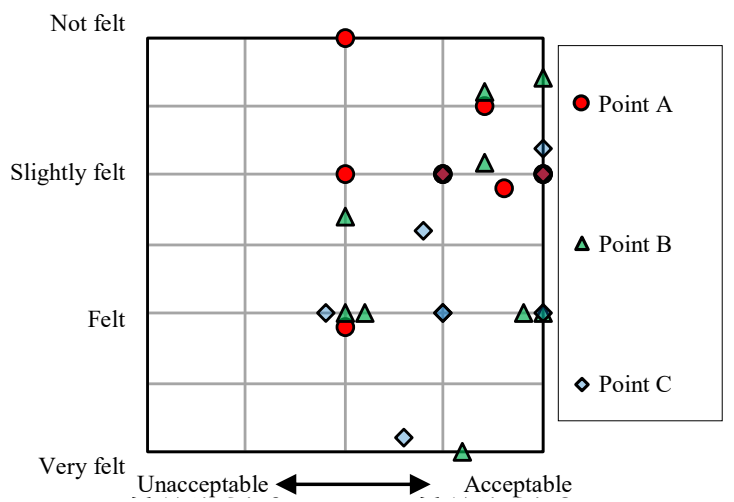

Fig. 10. Distribution of air flow sensation and acceptance

The thermal comfort perceived was overall adequate. In particular, the responded comfort level was high at the point where the air current lands on the upper body. Meanwhile, the comfort level deteriorates when the influence of the air flow is small and at the point where the air current lands on the lower body. Therefore, it is recommended for comfortable air conditioning to direct the air flow peeling from the ceiling not to blow toward the lower body.

\section{References}

1. Agency for Natural Resources and Energy, Strategic Energy Plan, 38 (2014) 
2. T. Akimoto, D. Hatori, N. Hirasuga, S. Kato, T. Ueda, Y. Sakamoto, Plan and Verification of a Midsize Office Aiming for ZEB (Part 1) Energysaving Building Facility Technologies on a Midsize Office, Technical Papers of The Society of Heating, Air-Conditioning and Sanitary Engineers of Japan, 10, 345-348 (2017)

3. H. Igarashi, T. Akimoto, D. Hatori, N, Hirasuga, A. Chiba, H. Takasu, S. Ohata, T. Ueda, Y. Sakamoto, S. Yamakita, Plan and Verification of a Midsize Office Aiming for ZEB (Part 5) Indoor Environment and Air Flow Characteristics of the Variable-Air-Volume Air-Conditioning System using the Coanda Effect, Technical Papers of The Society of Heating, Air-Conditioning and Sanitary Engineers of Japan, 10, 361-364 (2017)

4. The Society of Heating, Air-Conditioning and Sanitary Engineers of Japan, Mechanism of the Comfortable Thermal Environment - aiming for the Rich Living Environment, 113-118 (2006) (in Japanese)

5. Architectural Institute of Japan, AIJES-H0004-2014, 3-19 (2014)

6. The Society of Heating, Air-Conditioning and Sanitary Engineers of Japan, Heating, AirConditioning and Sanitary Engineering Handbook $14^{\text {th }}$ Edition, 1, 339 (in Japanese) 